\title{
PREVALENCE OF 25-HYDROXY VITAMIN D DEFICIENCY AND SOME BIOCHEMICAL PARAMETERS IN IRAQI PATIENTS WITH RHEUMATOID ARTHRITIS AND THEIR ASSOCIATIONS WITH DISEASE ACTIVITY
}

\author{
ABDULNASSER M AL-GEBORI ${ }^{1 *}$, MOHAMMED HADI MUNSHED ALOSAMI ${ }^{2}$, NAWAL HAIDER AL-HASHIMI ${ }^{1}$ \\ ${ }^{1}$ Department of Applied Science, Branch of Applied Chemistry, University of Technology, Baghdad, Iraq. ${ }^{2}$ Department of Medicine, \\ Rheumatology Unit, Colleges of Medicine, University of Baghdad, Baghdad, Iraq. Email: abdulnasser_238@yahoo.com
}

Received: 02 January 2020, Revised and Accepted: 22 February 2020

\section{ABSTRACT}

Objectives: The objectives of the study were to evaluate changes in 25(OH) Vitamin D levels and some biochemical parameters in rheumatoid arthritis (RA) patients compared with healthy controls and assess the correlation of 25-hydroxy Vitamin D, calcium, magnesium, and disease activity. Study the effects of anti-RA drugs on these biochemical parameters and also the role of supplements calcium and 25-OH Vitamin D in RA patients.

Methods: This study conducted between 60 patients for RA and 20 healthy controls according to the American College of Rheumatology standards in 2010. In this study, 25-hydroxy Vitamin D was measured using an enzyme-linked immunosorbent assay, and also some biochemical parameters were measured with a spectrophotometer (Humalyzer 2000).

Results: Serum 25(OH) Vitamin D, calcium, magnesium, and albumin levels were significantly lower in RA patients compared with healthy controls. Serum alanine aminotransferase aspartate aminotransferase levels were significantly increased in RA patients compared with healthy controls. The correlation was non-significantly among 25-hydroxy Vitamin D and clinical disease activity index (CDAI), while the results showed significantly inverse correlation calcium and magnesium concentrations with CDAI.

Conclusion: 25-OH Vitamin D, calcium, albumin, and magnesium deficiency appear to be widespread in patients with RA. Thus, biochemical changes in RA are reflected in the pathogenesis of RA. Furthermore, in these results, there is no relationship between Vitamin D and the disease activity, while there is a relationship between calcium and magnesium with disease activity.

Keywords: Rheumatoid arthritis, 25-hydroxy vitamin D, Calcium, Magnesium, Albumin, Aspartate aminotransferase, Alanine aminotransferase.

(c) 2020 The Authors. Published by Innovare Academic Sciences Pvt Ltd. This is an open access article under the CC BY license (http://creativecommons. org/licenses/by/4. 0/) DOI: http://dx.doi.org/10.22159/ajpcr.2020.v13i4.36759

\section{INTRODUCTION}

Rheumatoid arthritis (RA) is serious and threatens to health worldwide, where RA is considered a pathological condition that attacks the immune system and affects the articular membrane leads to the secretion of cytokine glycoproteins that cause cartilage erosion and osteoporosis adjacent to the affected joint [1]. Vitamin D is one of the main vitamins that soluble in fat [2,3]. Given the important roles of Vitamin D at the human corpus including maintaining healthy bone, activates the body's immune system, prevents osteoporosis, and increases bone density, and promotes the absorption of minerals and calcium from the intestine [4]. Recently, Vitamin D deficiency has become difficult to ignore, where the previous studies have shown that long-term Vitamin D deficiency causes RA, cancers, obesity, and affects the work efficiency of the insulin [5-7]. Calcium has benefits in bone building and its role in the health of the muscles, heart [8], but the role of calcium is not yet clear in RA, perhaps this is due to the changes occurring in the bone as a result of affected by RA [9]. Magnesium (Mg) is an essential mineral needed by the body to perform its functions [10]. Magnesium has multiple functions in the body, including contributes to bone formation, supports the immune system, and increases its ability to resist diseases [11]. Albumin (Alb): Is one of the essential proteins found in the blood. Albumins are produced in the liver and stimulation by hormones such as cortisol, insulin, and growth hormone $[12,13]$. The aspartate aminotransferase (AST) and alanine aminotransferase (ALT) are enzymes found at the cells of the body, especially in the liver and also found in the heart, kidney, brain, pancreas, red blood cells, and muscle tissue. High ALT and AST levels are mainly associated with liver damage or body tissue, so when the liver cells or body tissues to are exposed to damage, the higher rate of ALT and AST is released into the bloodstream [14].

\section{METHODS}

\section{Study design}

The present study was conducted at Baghdad Teaching Hospital/City of Medicine from September 2018 to January 2019. This study included 80 blood samples, 60 of which were Iraqi patients with RA ( 49 females and 11 males), and 20 samples for healthy controls (16 females and four males). Patients with RA were diagnosed by consultant rheumatologists; according to American College of Rheumatology (ACR) standards in 2010, information related to RA disease was collected such as gender, age, duration of disease, type of treatment, and measurement disease activity by clinical disease activity index (CDAI).

This study was approved by the ethics committee before work begins.

\section{Sample collection}

Five milliliters of blood were withdrawn from RA patients and healthy controls. The blood sample was placed at a gel tube and left at $25^{\circ} \mathrm{C}$ until blood clotted and then placed in a centrifuge at $3000 \mathrm{rpm}$ for $10 \mathrm{~min}$. After that, the serum was placed at small tubes (Eppendorf) and stocked at $-40^{\circ} \mathrm{C}$. Enzyme,-linked immunosorbent, assay according to CALBIOTECH was utilized to detect antibody 25-hydroxy-Vitamin D and using a spectrophotometer (Humalyzer 2000) for the measurement of calcium, magnesium, albumin, AST, and ALT. 
Table 1: Comparison between serum 25-0H Vitamin D and biochemical parameters in RA patients and healthy controls

\begin{tabular}{lll}
\hline Parameters & RA patients $(\mathbf{n = 6 0 )}$ mean $\mathbf{S D}$ & Healthy control $(\mathbf{n = 2 0})$ mean \pm SD \\
\hline 25-OH Vitamin D (ng/mL) & $8.39 \pm 2.37$ & $10.14 \pm 4.01$ \\
Calcium (mg/dL) & $6.75 \pm 0.79$ & $7.93 \pm 0.72$ \\
Magnesium (mg/dL) & $2.04 \pm 0.34$ & $2.26 \pm 0.20$ \\
Albumin (g/L) & $39.57 \pm 8.21$ & $43.99 \pm 4.28$ \\
ALT (U/L) & $28.04 \pm 18.45$ & $21.95 \pm 5.10$ \\
AST (U/L) & $25.72 \pm 13.10$ & $20.10 \pm 5.06$ \\
\hline
\end{tabular}

RA: Rheumatoid arthritis, SD: Standard deviation, n: Number, ALT: Alanine aminotransferase, AST: Aspartate aminotransferase, ${ }^{*} \mathrm{p} \leq 0.05,{ }^{* * *} \mathrm{p} \leq 0.001$

\section{Exclusion criteria}

In this study, patients with epilepsy, heart disease, migraine, and thyroid disorders were excluded from the study.

\section{Statistical analysis}

Data analysis was performed using the SPSS statistical program, (Version/11.5; SPSS Inc., Chicago, IL). Analysis of variance (ANOVA) was used to determine whether there are any statistically significant differences among the means. Data were presented as mean \pm standard error. Pearson's correlation (r-correlation) was used between 25-hydroxy-Vitamin D, calcium, magnesium, and CDAI. $\mathrm{p} \leq 0.05$ was considered statistically significant.

\section{RESULTS}

In this study, the results showed a significantly decreased in serum 25$\mathrm{OH}$ Vitamin D, calcium, magnesium, and albumin levels in RA patients compared with healthy controls, while the results showed a significantly increased in serum ALT and AST levels in RA patients compared with healthy controls in Table 1.

Fig. 1 shows the serum level of 25-OH Vitamin D in RA patients with different drugs. The mean and stander deviation (SD) values for patients treated with methotrexate (MTX) $10.03 \pm 1.84 \mathrm{ng} / \mathrm{mL}$; patients treated with Etanercept-MTX $9.22 \pm 2.96 \mathrm{ng} / \mathrm{mL}$; patients treated with Etanercept $7.05 \pm 1.38 \mathrm{ng} / \mathrm{mL}$; and patients treated with prednisoloneEtanercept- MTX $7.14 \pm 1.07 \mathrm{ng} / \mathrm{mL}$. These results noted that a significantly low ( $p=0.021$ ) serum level of $25-0 H$ Vitamin $D$ is more in both patients treated with (Etanercept) and patients treated with prednisolone-Etanercept-MTX compared with patients treated with MTX and patients treated with Etanercept-MTX.

Fig. 2 shows the serum level of calcium in patients with different drugs. The mean and SD values for patients treated with (MTX) $7.15 \pm 0.60 \mathrm{mg} / \mathrm{dL}$; patients treated with Etanercept-MTX $7.07 \pm 0.55 \mathrm{mg} / \mathrm{dL} ;$ patientstreated with Etanercept $5.85 \pm 1.52 \mathrm{mg} / \mathrm{dL}$; and patients treated with prednisolone-Etanercept-MTX $6.62 \pm 0.94 \mathrm{mg} / \mathrm{dL}$. These results noted that a significantly low $(\mathrm{p}=0.045)$ level of calcium is more in both patients treated with Etanercept and patients treated with prednisolone-Etanercept-MTX compared with patients treated with MTX and patients treated with Etanercept-MTX.

Fig. 3 shows the serum level of albumin in RA patients with different drugs. The mean and SD values for patients treated with MTX $44.06 \pm 6.38 \mathrm{~g} / \mathrm{L}$; patients treated with Etanercept-MTX 43.09 $\pm 7.74 \mathrm{~g} / \mathrm{L}$; patients treated with Etanercept $33.50 \pm 9.32 \mathrm{~g} / \mathrm{L}$; and patients treated with prednisolone-Etanercept-MTX $35.65 \pm 7.60 \mathrm{~g} / \mathrm{L}$. In these results, noted that a significantly low $(\mathrm{p}=0.001)$ level of albumin is more in both patients treated with Etanercept and patients treated with prednisolone-Etanercept-MTX compared with patients treated with MTX and patients treated with Etanercept-MTX.

Fig. 4 shows the serum level of ALT in RA patients with different drugs. The mean and SD values for patients treated with MTX 26.86 $\pm 9.47 \mathrm{U} / \mathrm{L}$; patients treated with Etanercept-MTX $35.45 \pm 25.51 \mathrm{U} / \mathrm{L}$; patients treated with Etanercept $21.03 \pm 6.05 \mathrm{U} / \mathrm{L}$; and patients treated with prednisolone-Etanercept-MTX $22.65 \pm 13.08 \mathrm{U} / \mathrm{L}$. In these results, noted that the increased level of ALT is more in both patients treated with

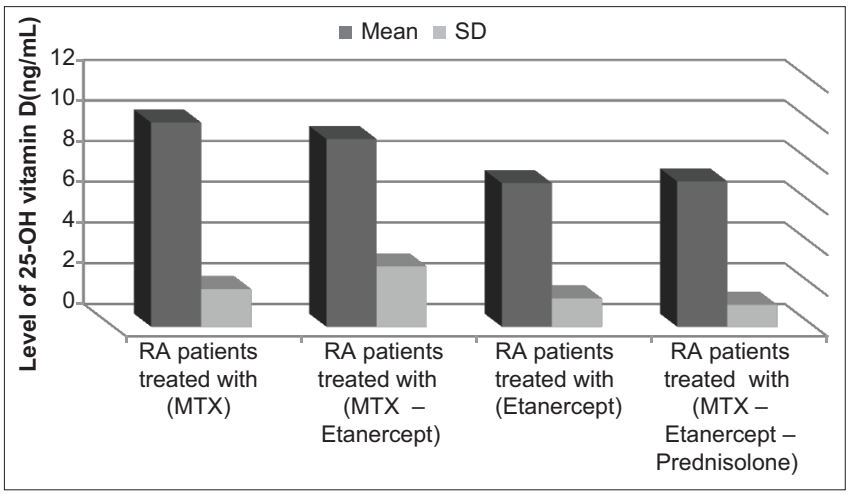

Fig. 1: Serum level of 25-0H Vitamin D in rheumatoid arthritis patients with different drugs

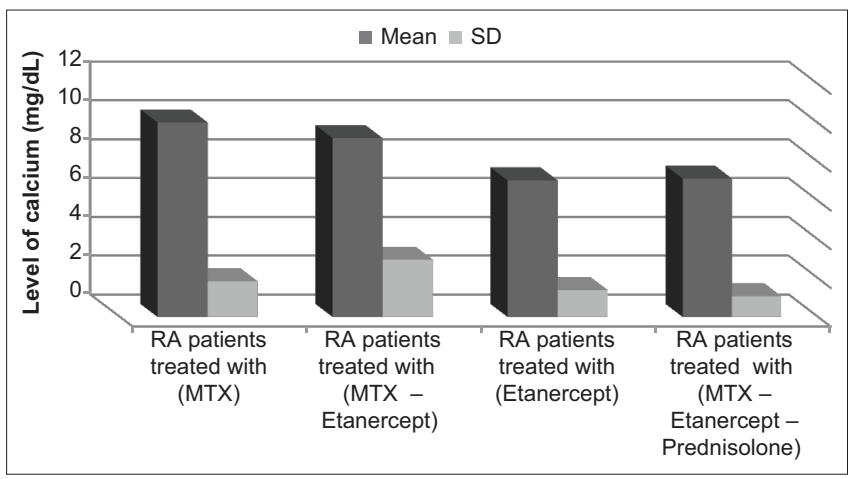

Fig. 2: Serum level of calcium in rheumatoid arthritis patients with different drugs

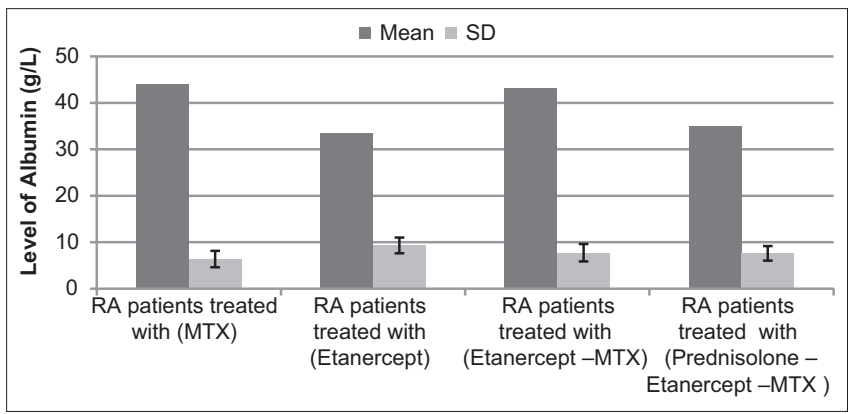

Fig. 3: Serum level of albumin in rheumatoid arthritis patients with different drugs

MTX and patients treated with Etanercept-MTX compared with patients treated with Etanercept and patients treated with prednisoloneEtanercept-MTX.

Fig. 5 shows the serum level of AST in RA patients with different drugs.

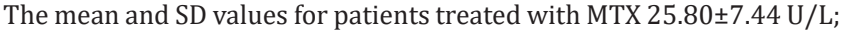




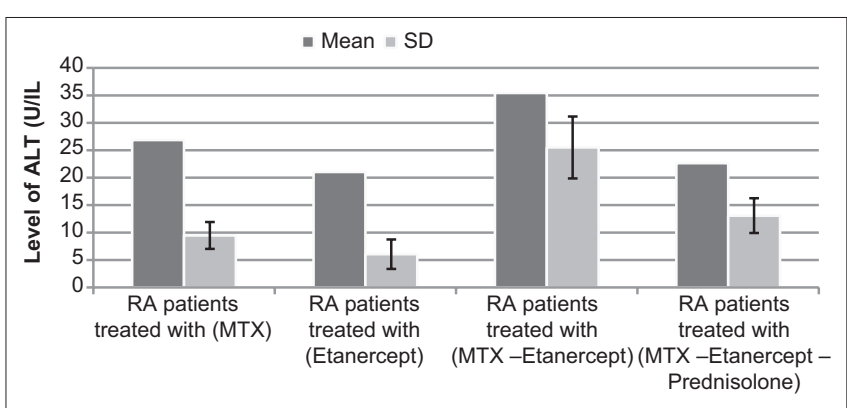

Fig. 4: Serum level of alanine aminotransferase in rheumatoid arthritis patients with different drugs

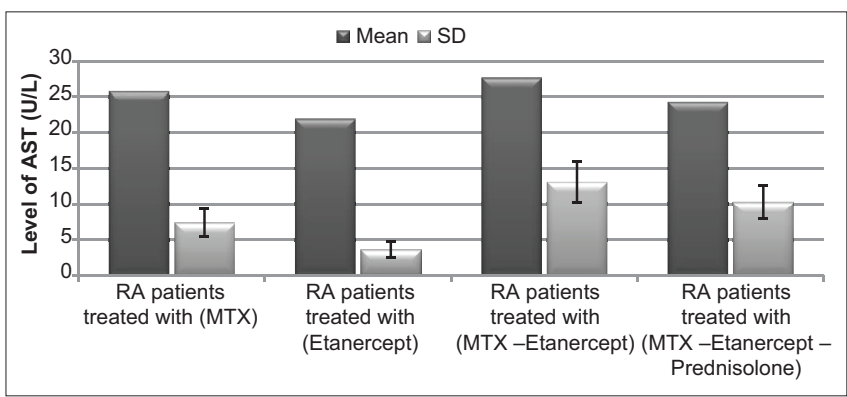

Fig. 5: Serum level of aspartate aminotransferase in rheumatoid arthritis patients with different

patients treated with Etanercept-MTX 27.73 $\pm 13.0 .8 \mathrm{U} / \mathrm{L}$; patients treated with Etanercept $21.98 \pm 3.63 \mathrm{U} / \mathrm{L}$; and patients treated with prednisolone-Etanercept-MTX $24.47 \pm 10.29 \mathrm{U} / \mathrm{L}$. In these results, noted that the increased level of AST is more in both patients treated with MTX and patients treated with Etanercept-MTX compared with patients treated with Etanercept and patients treated with prednisoloneEtanercept-MTX.

Table 2 shows the comparison of serum level of 25-OH Vitamin D between RA patients with Vitamin D supplementation and RA-patients without Vitamin D supplementation. The mean and SD values for RA patients with Vitamin D supplementation $20.03+5.21 \mathrm{ng} / \mathrm{mL}$ and $\mathrm{RA}$ patients non-Vitamin D supplementation $8.39 \pm 2.37 \mathrm{ng} / \mathrm{mL}$. The results showed a significantly increased $(p=0.001)$ in RA patients with Vitamin D supplementation compared to RA patients non-Vitamin D supplementation.

Table 3 shows the comparison of serum level of calcium between RA patients with calcium supplementation and RA patients withou calcium supplementation. The mean and SD values for RA patients with calcium supplementation $8.28 \pm 0.72 \mathrm{mg} / \mathrm{dL}$ and $\mathrm{RA}$ patients non calcium supplementation $6.75 \pm 0.7 \mathrm{mg} / \mathrm{dL}$. The results showed a significantly increased $(\mathrm{p}=0.001)$ in $\mathrm{RA}$ patients with

calcium supplementation compared to RA patients without calcium supplementation.

Data, as shown in Table 4, the correlation between the concentration of 25-OH Vitamin D, calcium, magnesium, and disease activity by (CDAI) in RA patients were assessed. The results showed a non-significantly correlation between $25-\mathrm{OH}$ Vitamin $\mathrm{D}(\mathrm{r}=0.18, \mathrm{p}=0.385)$ and CDAI in RA patients, while in the results showed a significant inverse correlation between calcium $(\mathrm{r}=-0.67, \mathrm{p}=0.0001)$, magnesium $(\mathrm{r}=-0.52, \mathrm{p}=0.0001)$, and CDAI in RA patients.

\section{DISCUSSION}

The results of this study agree with the previous, where these studies showed a low level of 25-OH Vitamin D in patients with RA compared with healthy controls $[15,16]$. Recently, low levels of 25-OH Vitamin D have been observed in RA patients and as known that Vitamin D is a
Table 2: Comparison of serum levels of 25-hydroxy Vitamin D between Vitamin D supplementation and non-Vitamin D supplementation in RA patients

\begin{tabular}{llll}
\hline Parameters & $\begin{array}{l}\text { RA patients } \\
\text { with Vitamin D } \\
\text { supplementation } \\
(\mathbf{n}=\mathbf{2 5}) \text { mean } \pm \text { SD }\end{array}$ & $\begin{array}{l}\text { RA patients } \\
\text { without Vitamin D } \\
\text { supplementation } \\
(\mathbf{n}=\mathbf{3 5}) \text { mean } \pm \text { SD }\end{array}$ & p-value \\
\hline $\begin{array}{l}\text { 25-Hydroxy } \\
\text { Vitamin D (ng/mL) }\end{array}$ & $20.03+5.21$ & $8.39 \pm 2.37$ & $0.001^{* *}$ \\
\hline RA: Rheumatoid arthritis, SD: Stander deviation, ${ }^{* *}$ p $\leq 0.001, \mathrm{n}$ : Number
\end{tabular}

Table 3: Serum level calcium between RA patients (with calcium supplementation) and RA patients (without calcium supplementation)

\begin{tabular}{llll}
\hline Parameters & $\begin{array}{l}\text { RA patients } \\
\text { with calcium } \\
\text { supplementation } \\
(\mathbf{n}=25) \text { mean } \pm \text { SD }\end{array}$ & $\begin{array}{l}\text { RA patients } \\
\text { without calcium } \\
\text { supplementation } \\
(\mathbf{n}=35) \text { mean } \pm \text { SD }\end{array}$ & p-value \\
\hline Calcium $(\mathrm{mg} / \mathrm{dl})$ & $8.28 \pm 0.72$ & $6.75 \pm 0.79$ & $0.001^{* * *}$ \\
\hline
\end{tabular}

RA: Rheumatoid arthritis, SD: Stander deviation, ${ }^{* * *} \mathrm{p}<0.001$, n: Number

Table 4: Correlation between 25-OH Vitamin D, calcium, magnesium concentration, and CDAI in RA patients

\begin{tabular}{lll}
\hline Parameters & r & p-value \\
\hline 25-OH Vitamin D & 0.18 & 0.385 N.S \\
Calcium (mg/dl) & -0.67 & $0.0001^{* * *}$ \\
Magnesium (mg/dl) & -0.52 & $0.0001^{* * *}$ \\
\hline
\end{tabular}

NS: Non-significant, r: Pearson correlation, ${ }^{* * *} \mathrm{p}<0.001$

stimulant for immune tolerance [17] and therefore Vitamin D deficiency affects immune tolerance, causing the development of autoimmune diseases (e.g., RA), Vitamin D is also known to have immune properties [18], so Vitamin D regulates the immune response through different mechanisms (e.g., stimulate regulatory $\mathrm{T}$ cells, decrease antigen presentation, and inhibit the pro-inflammatory $\mathrm{T}$ helper type 1 profile) $[19,20]$ so, the cause of $25-0 H$ Vitamin D deficiency in RA patients was due to several reasons; autoimmune diseases, which played a role in the low level of Vitamin D, and Vitamin D deficiency was associated with musculoskeletal pain [21,22], as well as found that RA patients treated with corticosteroids had a low level of Vitamin D, although the treatment of corticosteroids has a small effect on the level of Vitamin D, corticosteroids have lowered the level of Vitamin D in RA patients $[23,24]$. Besides, 25-OH Vitamin D deficiency was not limited to RA patients, but the healthy controls also suffered from 25$\mathrm{OH}$ Vitamin D deficiency, but the decline was only in healthy females, as shown in Table 1. The results of this study agree with a previous study [25] and they found decreased 25(OH) Vitamin D level in veiled women; therefore, 25(OH) Vitamin D deficiency in women was caused by the veil, little exposure to the sun, contraceptive pills and neglecting Vitamin D-containing foods [26]. As shown in Table 2, the results showed significantly increased in RA patients with Vitamin D supplement compared to RA patients without Vitamin D supplement, and the results of this study agree with the previous study [27]. Vitamin D supplement has contributed to the high level of Vitamin D in patients with RA as well as has a role in reducing the risk of osteoporosis [28].

As shown in Table 4, the results showed a non-significantly correlation between 25-OH Vitamin D and CDAI. The results of this study agree with previous studies, where the previous studies showed no association between Vitamin D and disease activity. Lack of Vitamin D may be a negative effect of bone health in RA patients [29,30]. Unlike, the previous study, the previous study showed a significant inverse relationship among serum Vitamin D levels and disease activity, and it 
considered that Vitamin D deficiency may be one of the reasons that lead to the development of the disease RA [31].

As shown in Table l, the decreased calcium level in RA patients a result agree with the literature [32] and the present study agrees with a previous study [33]. The reason of low level of calcium in RA patients was due to poor absorption of calcium from the intestines or the effect of glucocorticoid therapy, which given to RA patients caused osteoporosis and bone loss. In addition to glucocorticoid treatment prevents the absorption of calcium in the intestines and renal tubules, and this is done through mechanisms that depend on Vitamin D [34]. Besides, some authors point out that the lack of calcium level may not be due to the disease itself, sometimes it is because of the medications used in the treatment of RA [35], the data in Fig. 2 show increased bone loss in both RA patients treated with Etanercept and RA patients treated with MTX-Etanercept-Prednisolone, these drugs cause weakness of the intestinal calcium absorption and RA patients more at risk of osteoporosis complications [36]. As shown in Table 3, calcium supplementation contributed to high calcium levels in RA patients and patients with RA need calcium supplements to maintain healthy bones and teeth and prevent osteoporosis [37]

As shown in Table 4, the results showed a significant inverse correlation between calcium and CDAI. The result of this study agrees with the previous study [36], where the previous study showed the correlation of low calcium level with disease activity in patients treated with corticosteroids. The reason for this was due to osteoporosis correlation with RA, besides that, the risk of rheumatic drugs (MTX-Prednisolone), which caused a decline in calcium level in the blood. Osteoporosis is prevented by the use of active calcium therapy [38,39].

As shown in Table 1, the results showed a significantly decreased serum level of $\mathrm{Mg}$ as well as found a significant inverse correlation of $\mathrm{Mg}$ and CDAI. Inflammation, regardless of its etiology, can cause noticeable changes in the distribution of minerals, and therefore, RA is one of the chronic infections associated with mineral disturbances in serum and oxidative stress [33]. Low magnesium levels in RA patients may be linked to several reasons included chronic inflammatory conditions that change the level of $\mathrm{Mg}$ and potential mechanism for reducing $\mathrm{Mg}$ in RA due to severe stress on cells in immune processes and the effect of RA disease on the bones directly, causing osteoporosis and therefore decrease magnesium and calcium in the blood. The result of this study agrees with the previous studies $[33,40]$.

As shown in Table 1, the results showed a significantly decreased albumin in RA patients comparison with healthy controls and the results of this study agree with the previous studies $[41,42]$, where the previous study shows that the decrease of albumin in RA patients was not limited to liver disease and malnutrition because in both cases the albumin circulation rate decreases when there was a decrease of albumin in the blood. Thus, the lower albumin in RA patients was due to several reasons; impaired kidney function and reduced albumin synthesis, loss or increased catabolism, as well as corticosteroid therapy, leads to a lower level of albumin and maybe the loss of albumin in the fluid of inflammatory joints leading to the depletion of fluid the intravascular, therefore decreased concentration of serum albumin [42].

As shown in Table 1, the results showed a significantly increased ALT and AST in RA-patients compared to healthy controls. The results of this study agree with the previous study [43]. Rise of liver enzymes ALT and AST in RA patients was due to several reasons; damage to liver cells, which increases the effectiveness of AST/ALT enzymes in the blood [42], it may be due to the building of glycogen in liver cells as a result of fat accumulation and thus lead to cirrhosis of the liver and also abnormal changes in hepatocytes, where these changes lead to the release of liver enzymes in the blood. In addition to the effect of rheumatism treatment, which contributes to rising levels of ALT and AST, where the previous study showed that MTX treatment raised ALT and AST levels in RA patients [44].
Limitations of the study

The limitations of this study are small sample size as well as not available time to measure potassium, phosphorus, parathyroid hormone, and other signs that have a link to the inflammation of RA. In addition, no specific information was obtained from RA patients on dietary intake of magnesium.

\section{CONCLUSION}

In this study, the RA patients had lower levels of $25(\mathrm{OH})$ Vitamin D, calcium, magnesium, and albumin comparison with healthy controls. Increased levels ALT and AST in RA patients compared to healthy controls. Supplements helped raise $25(\mathrm{OH})$ Vitamin D and calcium levels in RA patients. The supplements can be used as adjunctive therapy with rheumatic treatment. Furthermore, it can be considered a substance that helps strengthen and maintain joints and bones. A negative correlation among 25-hydroxy Vitamin D and disease activity by CDAI was found in patients with RA, while a positive correlation was found among calcium, magnesium levels, and CDAI. Therefore, we conclude from this study that the reason for the decrease is due to changes in the joints as a result of the development of the disease RA.

\section{ACKNOWLEDGMENT}

The authors are grateful to the Applied Chemistry Branch, Department of Applied Science, University of Technology, staff in the rheumatology ward, staff educational laboratory, and staff blood bank at Baghdad Teaching Hospital, for providing facilities.

\section{AUTHORS' CONTRIBUTIONS}

Authors Abdulnasser M. Al-Gebori and Mohammed Hadi Munshed Alosami contributed to the original idea design of the study and facilitate the acquisition of samples of healthy controls and RA patients according to ACR standards in 2010. Nawal Haider Al-Hashimi was responsible for carrying out the work and performing all the tests of the above-mentioned patients. All authors contributed to the interpretation of data and manuscript writing

\section{CONFLICTS OF INTEREST}

Nil.

\section{REFERENCES}

1. Tobón GJ, Youinou P, Saraux A. The environment, geo-epidemiology, and autoimmune disease: Rheumatoid arthritis. Autoimmun Rev 2010;9:A288-92

2. Wong TH, Gupta ED, Radhakrishnan AK, Gun SC, Chembalingam G, Yeap SS. Effects of 25-hydroxyvitamin D and vitamin D-binding protein on bone mineral density and disease activity in Malaysian patients with rheumatoid arthritis. Int J Rheum Dis 2018;21:992-1000.

3. Hossein-nezhad A, Holick MF. Optimize dietary intake of Vitamin D: An epigenetic perspective. Curr Opin Clin Nutr Metab Care 2012; $15: 567-79$

4. Peters BS, Verly E Jr., Marchioni DM, Fisberg M, Martini LA. The influence of breakfast and dairy products on dietary calcium and Vitamin D intake in postpubertal adolescents and young adults. J Hum Nutr Diet 2012;25:69-74.

5. Elsammak MY, Al-Wosaibi AA, Al-Howeish A, Alsaeed J. Vitamin D deficiency in Saudi Arabs. Horm Metab Res 2010;42:364-8.

6. Hossein-Nezhad A, Holick MF. Vitamin D for health: A global perspective. 2013;88:720-55

7. Alshahrani AA. Vitamin D Deficiency and Possible Risk Factors among Middle Eastern University Students in London, Ontario, Canada.' Electronic Thesis and Dissertation Repository; 2014.

8. Benkhedda K, L'abbé MR, Cockell KA. Effect of calcium on iron absorption in women with marginal iron status. $\mathrm{Br} \mathrm{J}$ Nutr 2010;103:742-8

9. Gröber U, Schmidt J, Kisters K. Magnesium in prevention and therapy. Nutrients 2015;7:8199-226.

10. Boyle NB, Lawton C, Dye L. The effects of magnesium supplementation on subjective anxiety and stress-a systematic review. Nutrients 2017;9:429. 
11. Castiglioni S, Cazzaniga A, Albisetti W, Maier JA. Magnesium and osteoporosis: Current state of knowledge and future research directions. Nutrients 2013;5:3022-33.

12. Fanali G, di Masi A, Trezza V, Marino M, Fasano M, Ascenzi P. Human serum albumin: from bench to bedside. Mol Aspects Med 2012;33:209-90.

13. Boldt J. Use of albumin: An update. Br J Anaesth 2010;104:276-84.

14. Huang XJ, Choi YK, Im HS, Yarimaga O, Yoon E, Kim HS. Aspartate aminotransferase (AST/GOT) and alanine aminotransferase (ALT/ GPT) detection techniques. Sensors 2006;6:756-82.

15. Hamad BA. Relationship between Vitamin D3 level and rheumatoid arthritis patients attending Rizgary Teaching Hospital in Erbil city. Zanco J Med Sci 2017;21:1736-42.

16. Allam NT, El-Wakd MM, El-Abd DM, Dorgham DA. Prevalence of Vitamin D deficiency in Egyptian rheumatoid arthritis patients: Correlation with disease activity, functional disability, and bone mineral density. Egypt Rheumatol Rehabil 2014;41:92.

17. Weiss ST. Bacterial components plus Vitamin D: The ultimate solution to the asthma (autoimmune disease) epidemic? J Allergy Clin Immunol 2011;127:1128-30.

18. Hewison M. Vitamin D and immune function: Autocrine, paracrine or endocrine? Scand J Clin Lab Invest Suppl 2012;243:92-102.

19. Bartels LE, Hvas CL, Agnholt J, Dahlerup JF, Agger R. Human dendritic cell antigen presentation and chemotaxis are inhibited by intrinsic 25-hydroxy Vitamin D activation. Int Immunopharmacol 2010;10:922-8

20. Correale J, Ysrraelit MC, Gaitán MI. Immunomodulatory effects of Vitamin D in multiple sclerosis. Brain 2009;132:1146-60.

21. Song GG, Bae SC, Lee YH. Association between Vitamin D intake and the risk of rheumatoid arthritis: A meta-analysis. Clin Rheumatol 2012;31:1733-9.

22. Hirani V. Vitamin D status and pain: Analysis from the health survey for England among English adults aged 65 years and over. Br J Nutr 2012;107:1080-4.

23. Gröber U, Kisters K. Influence of drugs on Vitamin D and calcium metabolism. Dermatoendocrinol 2012;4:158-66.

24. Davidson ZE, Walker KZ, Truby H. Clinical review: Do glucocorticosteroids alter Vitamin D status? A systematic review with meta-analyses of observational studies. J Clin Endocrinol Metab 2012;97:738-44

25. Ahmed MK, Al-Osami MH. Vitamin D Level in Veiled and Unveiled Iraqi Young Females. Baghdad: University of Baghdad; 2017.

26. Canadian Health Measures Survey. Vitamin D Status of Canadians Vitamin D Nutrients in Milk Products Dairy Nutrition. Dairy Nutrition RSS Government, Canadian Health Measures Survey; 2013.

27. Kostoglou-Athanassiou I, Athanassiou P, Lyraki A, Raftakis I, Antoniadis C. Vitamin D and rheumatoid arthritis. Ther Adv Endocrinol Metab 2012;3:181-7.

28. Ringe JD. The effect of Vitamin D on falls and fractures. Scand J Clin
Lab Invest Suppl 2012;243:73-8.

29. Aref IM, Eissa HA, Bayomi IM, Fawzi MM, et al. Relationship between Vitamin D and rheumatoid arthritis activity. Vitam Miner 2017;6:168.

30. Quraishi MK, Badsha H. Rheumatoid arthritis disease activity and Vitamin D deficiency in an Asian resident population. Int J Rheum Dis 2016;19:348-54.

31. Meena N, Singh Chawla SP, Garg R, Batta A, Kaur S. Assessment of Vitamin D in rheumatoid arthritis and its correlation with disease activity. J Nat Sci Biol Med 2018;9:54-8.

32. Makhdoom A, Rahopoto MQ, Laghari MA, QureshiPir AL, Siddiqui KA. Bone mineral levels in rheumatoid arthritis. Med Channel 2009;15:99-102.

33. Chavan VU, Ramavataram D, Patel PA, Rupani MP. Evaluation of serum magnesium, lipid profile and various biochemical parameters as risk factors of cardiovascular diseases in patients with rheumatoid arthritis. J Clin Diagn Res 2015;9:BC01-5.

34. Hoenderop JG, Nilius B, Bindels RJ. Calcium absorption across epithelia. Physiol Rev 2005;85:373-422.

35. Walwadkar SD, Suryakar AN, Katkam RV, Kumbar KM, Ankush RD. Oxidative stress and calcium-phosphorus levels in rheumatoid arthritis. Indian J Clin Biochem 2006;21:134-7.

36. Reid DM, Kennedy NS, Smith MA, Tothill P, Nuki G. Total body calcium in rheumatoid arthritis: Effects of disease activity and corticosteroid treatment. Br Med J (Clin Res Ed) 1982;285:330-2.

37. Suzuki T, Nakamura Y, Kato H. Calcium and Vitamin D supplementation with 3-year denosumab treatment is beneficial to enhance bone mineral density in postmenopausal patients with osteoporosis and rheumatoid arthritis. Ther Clin Risk Manag 2019;15:15-22.

38. Yilmaz L, Ozoran K, Gündüz $\mathrm{OH}$, Uçan $\mathrm{H}$, Yücel $\mathrm{M}$. Alendronate in rheumatoid arthritis patients treated with methotrexate and glucocorticoids. Rheumatol Int 2001;20:65-9.

39. Lucia M, Isabela S, Minerva G. Changes of serum magnesium level in patients with rheumatoid arthritis stage I-II before treatment. Med Conn 2011;6:9-16.

40. Cortés YE, Moses L. Magnesium disturbances in critically ill patients. Compend Contin Educ Vet 2007;29:420-7.

41. Koo BS, Hong S, Kim YJ, Kim YG, Lee CK, Yoo B. Clinical characteristics of patients with rheumatoid arthritis who have sustained high erythrocyte sedimentation rates after clinical remission. J Rheum Dis 2014;21:21-24.

42. Wilkinson P, Jeremy R, Brooks FP, Hollander JL. The mechanism of hypoalbuminemia in rheumatoid arthritis. Ann Intern Med 1965;63:109-14

43. Curtis JR, Beukelman T, Onofrei A, Cassell S, Greenberg JD, Kavanaugh A, et al. Elevated liver enzyme tests among patients with rheumatoid arthritis or psoriatic arthritis treated with methotrexate and/or leflunomide. Ann Rheum Dis 2010;69:43-7.

44. Limdi JK, Hyde GM. Evaluation of abnormal liver function tests. Postgrad Med J 2003;79:307-12 